ISI Impact Factor

(2019-20): 1.628

IC Value (2019): 90.81

$\operatorname{SJIF}(2020)=7.893$

(c) (i) (3)

Copyright@IJCRR

\section{$\bullet$ \\ IJCRR \\ Section: Healthcare \\ Perspectives of Students and Teaching Faculty Members Towards the New MBBS Curriculum in a Tertiary Care Hospital in Chennai}

\author{
Preetha Selva ${ }^{1}$, Rithikaa M $^{2}$
}

'Associate Professor, Department of Pharmacology, Saveetha Medical College and Hospital, SIMATS, Chennai 602 105, India; ${ }^{2}$ nd-year MBBS

Student, Saveetha Medical College and Hospital, SIMATS, Chennai 602 105, India.

\title{
ABSTRACT
}

Introduction: The medical council of India has released a new curriculum for medical undergraduate students titled "Competency-based UG Curriculum for the Indian Medical Graduates". This curriculum which bestows outcome-based strategy is implemented to improve the quality of medical education thereby providing more efficient future doctors.

Objectives: To assess the knowledge, attitude and perspectives of students and teaching faculty members of our institution towards the newly implemented MBBS curriculum.

Methods: A pre-validated questionnaire in the form of electronic form submission was sent to all the participants online based on inclusion criteria during the study period. The responses were assessed and analyzed.

Results: Out of the 885 students and faculty members altogether who had received the questionnaire, only 594 had participated and given their opinions. The knowledge, attitude and perspectives of the participants towards the new curriculum were assessed.

Conclusion: The new curriculum is specially designed to make the medical graduates' workplace ready and competent. Therefore, to keep up with the global standards, we cannot procrastinate from the implemented curriculum as it is the need of the hour. The awareness, advantages, necessity and outcomes of competency-based medical education can be improved by conducting sensitization programs such as curriculum implementation support programs for all the teaching faculty members. Since, it is difficult to cope up with the sudden transition to the newly implemented curriculum, as it requires tedious planning, downtime, manpower, and changes in the teaching-learning process a hybrid approach can be considered in which the newly implemented CBME curriculum is incorporated into the existing conventional curriculum. This slow transition can allow time for better designing and implementation of the new curriculum as it would provide sufficient breathing space to analyze the advantages and better acceptance of the CBME curriculum among the faculty members which may lead to the evolution of robust change in the quality of medical education.

Key Words: Medical education, Curriculum-based medical education, Knowledge, Attitude, Perspectives, Questionnaire

\section{INTRODUCTION}

The medical education system is the mainstay of the health care sector which is deflected from its prime purpose of providing effective medication management due to lack of skilled medical faculty members and technicians and reduced quality and quantity of research in the field. ${ }^{1}$ Hence after a long period of twenty-one years, the Medical Council of India (MCI) has released a new curriculum for medical undergraduate students titled "Competency-based UG Curriculum for the Indian Medical Graduates."'This curriculum designed for college kids pursuing M.B.B.S was enacted in India from August 2019 which incorporates three volumes of 890 pages in total. According to the new curriculum, at the end of the course, an MBBS student must acquire a total of 2939 competencies. ${ }^{3}$ Resultantly, the MCI aims to provide scholars with a much better learning perspective by integrating the medical curriculum.

Early Clinical Exposure (ECE), Curriculum Implementation Support Program (CISP), Attitude Ethics and Communication Module (AETCOM), and Foundation Course are the quintessence of the new curriculum which is introduced of late. The quality of teaching at the grass-root level and col-

\section{Corresponding Author:}

Preetha Selva, Associate Professor, Department of Pharmacology, Saveetha Medical College and Hospital, SIMATS, Chennai 602 105, India. Contact: 9940170371; Email: drpreethaselva@gmail.com

ISSN: $2231-2196$ (Print)

Received: 25.09 .2020
ISSN: 0975-5241 (Online)

Revised: 18.11 .2020
Accepted: 21.12 .2020 
laborative studies in the backdrop with the clinical correlation of the disease is improved by Horizontal and Vertical combination of teaching in the newly implemented curriculum. It also helps to overlap the syllabus in various phases.

Medical Education Unit (MEU) could be a forum where all staffs of the Medical College including pre-clinical, paraclinical and clinical faculty members meet and contribute their knowledge through guest lectures and continued medical education. It includes faculty development programs (FDP) also.

The primary intention of the Foundation Course which is introduced to the students within the first two months of the primary year of MBBS incorporates orienting the undergraduates to all aspects of the medical college ambience; equipping them with certain fundamental yet significant skills required for patient care and enhancing their communication, language, computer, and learning skills; providing an opportunity for peer and faculty interactions and overall responsiveness to the varied learning methodologies.

Effective communication with the patients remains the key to success for medical professionals. The most defining characteristics of a medical student are his communication skills. A healthy patient-doctor relationship has a crucial role in the diagnosis, treatment and also satisfaction of the patient. The communication is expected to be sensitive, effective, respectful, informative, and should be adequate.

Problem-based learning (PBL) encompasses a great contribution to improving knowledge and learning skills and developing interpersonal communication and presentation skills. Assessment plays an important part in the new curriculum. MCI has forced to implement the Competency-based Medical Education (CBME) which focuses on the required and observable ability in real-life situations. Evaluation in an exceedingly Competency-based Medical Education focuses on enhancing learning as an ongoing process so that the faculty can spot it, make alternative measures and provide better learning opportunities to the students for their betterment. Various methods that can be followed to assess the students are through multiple-choice questions, casebased discussions, Theory tests, viva voce, skill assessment, OSCE, OSPE, seminars, assignments etc. ${ }^{4}$ Hence, the main purpose of implementing the new U.G curriculum is to give importance to all the three domains like cognitive, affective and psychomotor domain than focusing on cognitive domain alone as per old curriculum pattern.

Though the CBME is speeding up worldwide and is a glaciated transition in the existing approach to medical teaching and education, there may be a few limitations in implementing the same at the institutional level. It needs a shaping of teaching-learning structure and process to a great extent to shift from teacher-centred to a more student-centred curricu- lum and meet the requirements of lifelong learning which is a main competency of the new curriculum. ${ }^{5}$ The faculty members may be overwhelmed by this sudden change as there is a lot of effort to be put by them to redefine the teaching-learning methodology, integrate with other pre, para and clinical staff members and put scheduled timetable for the students based on competencies in the curriculum, constructing specific learning objectives and heuristic evaluation with productive feedback, designing logbooks and portfolios. This would require a lot of manpower, workforce and material to be carried out effectively. ${ }^{6}$ Though the students may be motivated to gain an understanding of medicine as they are exposed to the clinical side in the form of early clinical exposure right after completing their high school they may also face a few challenges which go neglected and are overlooked.

Since this curriculum is being recently introduced and there are only a very few studies done on the same we felt the need to assess the knowledge, attitude and perspectives of students and teaching faculty members of our institution towards the newly implemented MBBS curriculum considering the aforementioned issues. In the present study we aimed to assess the knowledge, attitude and perspectives of undergraduate medical students and teaching faculty members concerning the newly implemented MBBS curriculum

\section{MATERIALS AND METHODS}

\section{Study Design: Questionnaire-based study}

Study Place \& Duration: The study was conducted for a period of 4 months starting from March to July 2020 in Saveetha medical college and hospital

Sample Size: All the teaching faculty members and students of Saveetha medical college were included in the study.

\section{Ethical committee approval number: SMC/ IEC/2020/03/258}

\section{Study Population:}

Inclusion criteria: All the phase I M.B.B.S students (CBME Batch), $2^{\text {nd }}, 3^{\text {rd }}, 4^{\text {th }}$-year M.B.B.S students and students doing their internship and teaching faculty of pre-clinical, paraclinical and clinical subjects of our colleagues who have volunteered to participate in our study and filled the written informed consent were included in our study.

Exclusion criteria: Teaching faculty members and students who did not give informed consent to participate in the study were excluded.

\section{Procedure}

The study was carried out only after getting approval from the Institutional Ethics Committee. The questionnaire of our 
study was validated and approved by two faculty members of Professor cadre who are members of the Medical Education Unit (MEU) and Curriculum Implementation Support Program (CISP) for their expertise. The informed consent form with a brief summary of the purpose of our study was circulated to all the teaching faculty members and M.B.B.S students of our college. After giving written informed consent they were allowed to answer the validated questionnaire which was shared online in the form of google response forms. The responses recorded were then assessed and evaluated.

\section{RESULTS}

Out of the 885 students and faculty members altogether who had received the questionnaire, only 594 had participated and given their opinions. The gender distribution and profession of the participants are shown in Figure 1.

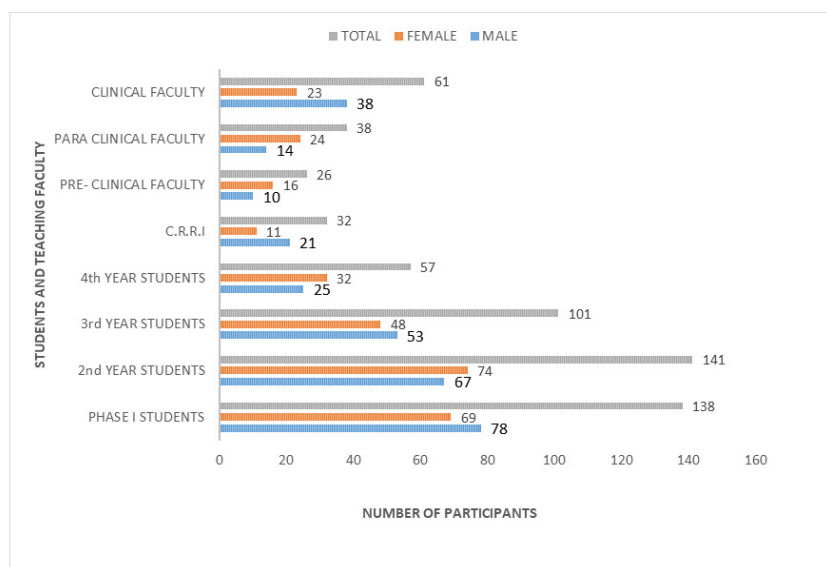

Figure 1: Distribution of gender and profession of participants.

The responses to the questionnaire based on knowledge, attitude and perspectives are shown below. Likert scale was used for a few questions in the questionnaire.

\section{KNOWLEDGE}

\section{QUESTIONS}

Are you aware of the new MBBS curriculum?

Early clinical exposure is a boon to budding doctors.

Did you know that foundation course, yoga and meditation has been brought up in the curriculum?

Early clinical exposure (ECE) allows the students to recognize the basic science in diagnosis, patient care and treatment.

Did you know that MCI has added the curriculum committee, CSC (curricular subcommittee) and AIT (alignment and integration team) to oversight the curriculum at institutional level.

Forensic medicine has been shifted to the 6th semester. Do you think it's better?

$\begin{array}{ccc}\text { YES } & \text { NO } & \text { MAYBE } \\ 492(82.9 \%) & 102(17.1 \%) & \\ 538(90.5 \%) & 56(9.4 \%) & \\ 427(71.8 \%) & 106(17.9 \%) & 61(10.3 \%)\end{array}$
$398(67.1)$
$53(8.9 \%)$
$143(24.01)$

$249(41.9 \%)$

$345(58.1 \%)$

$168(28.2 \%)$

$152(25.6 \%)$

$274(46.2 \%)$

Are you aware that in phase II, the students have 2 semesters instead of 3 ? 


\section{ATTITUDE:}

Assessment is a vital component of competency based medical education (CBME) to improve learning skills of the student

Boosts up the enthusiasm of students to set their professional career from the beginning

Electives provide opportunities for students to acquire diverse learning experiences coming years

Should it have been revised and implemented earlier?

$$
259(43.6 \%)
$$

The responses for the question Assessment is a vital component of competency-based medical education (CBME) to improve the learning skills of the student is depicted in fig 2. $18.8 \%$ and $58.1 \%$ of the participants strongly agreed \& agreed that assessment is important respectively.

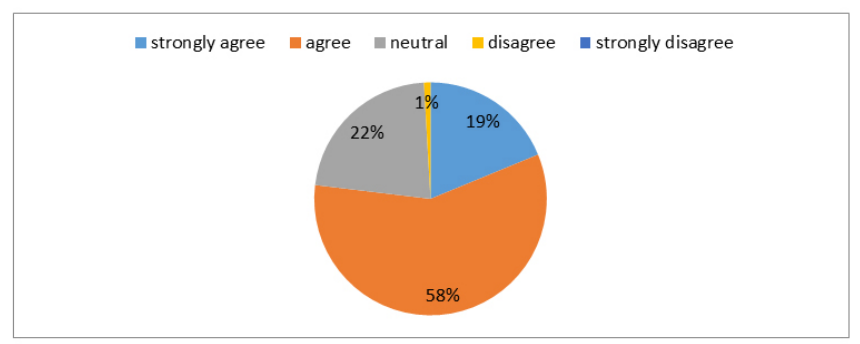

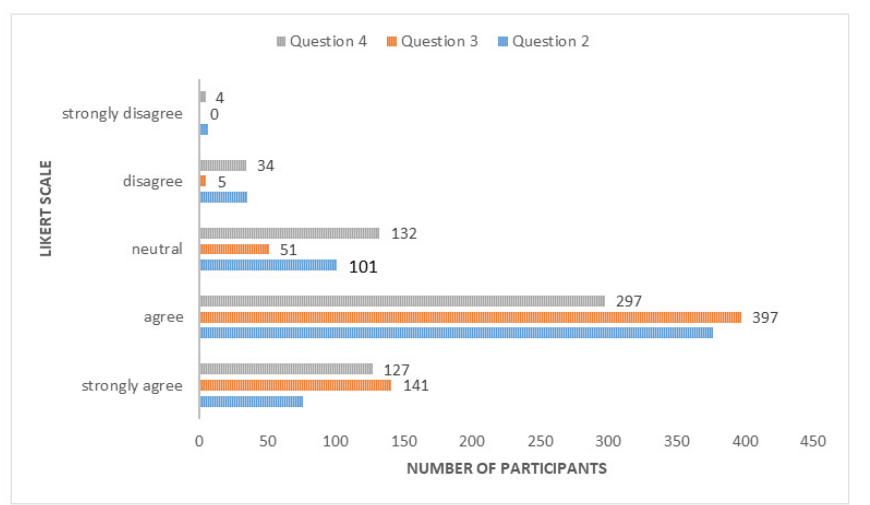

Figure 3: Responses to Attitude based question 2, 3 and 4 using Likert scale.

Figure 2: Response to attitude based question 1.

\section{PERSPECTIVES}

\section{QUESTIONS}

1. How much do you think AETCOM (attitude, ethics and communication) is necessary for a doctor

2. Vertical and horizontal integrations make the student understand the topic better.

3. ECE improves understanding, interaction and problem-solving skills. If no, why?

4. Problem-based learning(PBL) enhances the knowledge in a specific area at the micro-level

5. Do you think $360^{\circ}$ impact evaluation would contribute to creating a better doctor to society? If no, why?

6. I support the implementation of the new curriculum in MBBS that would be most helpful to achieve roles and goals of Indian medical graduate (IMG) at a stipulated time

7. I prefer the newly revised curriculum over the previous one

\begin{tabular}{|c|c|c|}
\hline AGREE & NEUTRAL & DISAGREE \\
\hline \multicolumn{3}{|l|}{ Fig 4} \\
\hline \multicolumn{3}{|l|}{ Fig 4} \\
\hline \multicolumn{3}{|l|}{ Fig 4} \\
\hline \multicolumn{3}{|l|}{ Fig 4} \\
\hline \multirow[t]{2}{*}{$330(55.6 \%)$} & $244(41 \%)$ & $20(3.4 \%)$ \\
\hline & & $26(4 \cdot 3 \%)$ \\
\hline $426(71.8 \%)$ & $142(23.9 \%)$ & $127(21.4 \%)$ \\
\hline
\end{tabular}

$467(78.6 \%)$ 


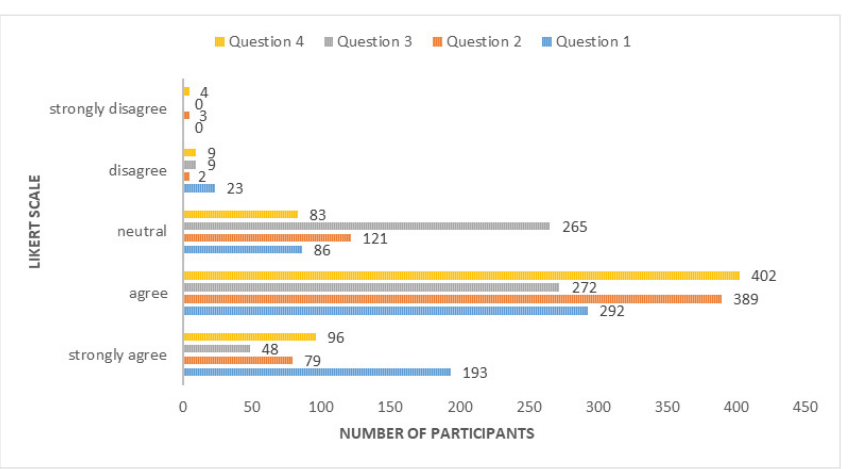

Figure 4: Responses to question 1,2,3,4 of Perspectives of faculty and students towards CBME.

\section{DISCUSSION}

Out of the 885 total number of faculty members and students studying Bachelor of Medicine and Bachelor of Surgery in our college and hospital only 594 of them who gave voluntary written informed consent were included in the study. The electronic submission of the response to the validated questionnaire to assess the knowledge, attitude and perspectives of the participants was collected and analyzed.

The response was more from phase I students who are currently in the newly implemented curriculum based medical education (CBME) batch and $2^{\text {nd }}$-year MBBS students equally compared to pre-final, final and students working as interns. Since phase I students are currently in the newly implemented curriculum batch they would be more aware and interested to answer the questionnaire related to the same. As we are teaching the $2^{\text {nd }}$ year MBBS students currently, increased interaction and communication with them may be the reason for more response from these set of students.

Though the list of faculty members in the clinical department is far more than the para and preclinical faculty members list, the relative response rate is low from the clinical faculty staffs. This may be because of more academic and professional socialization with the pre-clinical and para-clinical staff members making them respond better to our study.

\section{Knowledge}

Among the 594 participants in our study, 102(17.1\%) of them were not even aware of the new MBBS curriculum. They mostly comprised the final year students, interns and busy consultants working in the clinical side who are more involved in providing patient care than teaching the students. $538(90.5 \%)$ agreed that Early clinical exposure is a boon to budding doctors. Only 427 (71.8\%),249 (41.9\%), $168(28.2 \%)$ and $365(61.5 \%)$ of them knew that foundation course, yoga and meditation have been brought up in the curriculum, MCI has added the curriculum committee, CSC (curricular subcommittee) and AIT (alignment and in- tegration team) to oversight the curriculum at the institutional level, Forensic medicine has been shifted to the 6th semester and phase II students have 2 semesters instead of 3 respectively. This shows that the complete knowledge of faculty members and students towards the new curriculum is only to a limited extent. To increase the same, the faculty members should be encouraged and stimulated to enrol and participate in faculty development programs and Curriculum Implementation Support Program (CISP) which are being organized and conducted periodically in our institution. This will provide a framework and basic insight into the new curriculum put into effect from August 2019. ${ }^{8} 398(67.1 \%)$ of them felt that early clinical exposure (ECE) will allow the students to recognize the basic science in diagnosis, patient care and treatment. Hence they agree with the action taken by the Medical Council of India to introduce ECE in the Indian medical curriculum thus reducing the line of demarcation between preclinical and clinical subjects. This will enable the students to attain firsthand experience in clinical skills thus improving the clinical educational quality.

\section{Attitude}

$18.8 \%$ and $58.1 \%$ of the participants strongly agreed \& agreed that assessment is an important component of competency-based medical education (CBME) to improve the learning skills of the student respectively. The remaining participants who disagreed were mostly the phase I students who are currently pursuing the new curriculum. This is obviously because the students are scared and reluctant to overcome the obstacle of attending assessments which involves intense preparation and hard work. Presumably, they also do not want to accept the fact that they are being judged and feel that faculty members become more biased towards students who perform well and are superior at memorization. ${ }^{9}$ This issue can be solved by conducting assessments in the form of objective structured clinical examination (OSCE)/ objective structured practical examination (OSPE), multiplechoice questions, Quiz and scores based on student's day to day activities. This will circumvent the need for assessments in the form of theory examination and also generate interest and enthusiasm among the students to prepare for the same. They also invigorate higher-order thinking among the medical students. ${ }^{10}$

452, 538 and 424 participants agreed and strongly agreed that the new curriculum will boost up the enthusiasm of students to set their professional career from the beginning, Electives will provide opportunities for students to acquire diverse learning experiences and CBME will improve quality and standards of health management system in coming years respectively. This shows the faculty members and students benevolence to the much needed reform in medical curriculum in the form of Competency Based Medical Education (CBME). Majority of the participants also felt 
that the revised curriculum should have been implemented earlier to maximize the benefits of the same which focus on the graduate to master and excel in his profession. This would have provided a set of more competent medical practitioners committed to excellence, responsible and accountable to patients and functioned professionally as this type of education focuses mainly on outcome-based strategy. ${ }^{11}$

\section{Perspectives}

$485(193+292), 468(389+79)$ and $498(402+96)$ participants agreed that AETCOM (attitude, ethics and communication) is necessary for a doctor, Vertical and horizontal integrations make the student understand the topic better and Problem based learning(PBL) enhances the knowledge in a specific area at micro-level respectively. However, only 320 participants felt that early clinical exposure (ECE) improves overall understanding, interaction and problem-solving skills. 265 participants remained neutral to this question. As the majority of them felt that ECE is essential and should be employed only for selected topics; despite being unnecessary for all medical topics they require more manpower and are time and energy-consuming. Incorporating early clinical exposure only for topics that are deemed necessary can be followed initially to circumvent the sudden change in CBME and give enough time to weigh the pros and cons of the same. ${ }^{12,13}$

$330(55.65 \%), 426(71.8 \%)$ and $467(78.6 \%)$ of participants felt that $360^{\circ}$ impact evaluation would contribute to creating a better doctor to the society, implementation of the new curriculum in MBBS would be most helpful to achieve roles and goals of Indian medical graduate (IMG) at a stipulated time and prefer the newly revised curriculum over the previous one respectively. Only $55.65 \%$ of the participants felt that $360^{\circ}$ impact evaluation would contribute to creating a better doctor to the society because they felt that all-round impact evaluation was not only time-consuming but also unnecessary as Medicine is an ongoing learning practice. Knowledge, attitude and skills the graduate has on the field of specialization he finally chooses and his experience, commitment and heavy competition in the medical field will as a matter of course make him a better doctor. ${ }^{14,15} 78.6 \%$ of participants preferred the new curriculum over the previous one which is a welcome sign for the successful outcome of the revised CBME implemented.

\section{CONCLUSION}

The knowledge, attitude and perspectives of teaching faculty members and M.B.B.S students were validated and assessed using a questionnaire. The awareness, advantages, necessity and outcomes of the competency-based medical education can be improved by conducting sensitization programs and curriculum implementation support programs for all the teaching faculty members. Since, it is difficult to cope up with the sudden transition to the newly implemented curriculum, as it requires tedious planning, downtime, manpower, and changes in the teaching-learning process a hybrid approach can be considered in which the newly implemented CBME curriculum is incorporated into the existing conventional curriculum. This slow transition can allow time for better designing and implementation of the new curriculum as it would provide sufficient breathing space to analyze the advantages and better acceptance of the CBME curriculum among the faculty members which may lead to the evolution of robust change in the quality of medical education.

\section{ACKNOWLEDGEMENT}

We are extremely thankful to the faculty members and students of our college who gave their willingness and participated in the study by answering the questionnaire. We thank the members of the Institutional Ethics Committee for giving us the approval to conduct the study. We are also thankful to Professors of the General Medicine and Anatomy Department for their expertise invalidating our questionnaire.

\section{Conflict of Interest: None Declared}

Funding source: No funding source

Authors contribution: ${ }^{\mathrm{st}}$ author: The questionnaire for the study was prepared and validation and approval of the same was obtained from the experts in the field of medical education and ethics committee. The manuscript was prepared and sent for publication under the journal guidelines.

$2^{\text {nd }}$ author: The response for the questionnaire was collected from the students of different phases and the faculty members of the clinical and non-clinical departments of the institution.

\section{REFERENCES}

1. Mitra J, Saha I. Attitude and communication module in medical curriculum: rationality and challenges. Indian J Public Health 2016;60(2):95.

2. Medical Council of India: Competency-Based under Graduate Curriculum. 2019. [Last accessed on 2019 Feb 02]. https://www. mciindia.org/CMS/information-desk/for-colleges/ug-curriculum.

3. Kumar R. The tyranny of the Medical Council of India's new (2019) MBBS curriculum: Abolition of the academic discipline of family physicians and general practitioners from the medical education system of India. J Family Med Prim Care 2019;8(2):323-325.

4. Holmboe ES, Sherbino J, Long DM, Swing SR, Frank JR. The role of assessment in competency-based medical education. Med Teach 2010;32:676-82. 
5. Frank JR, Snell LS, Cate OT, Holmboe ES, Carraccio C, Swing SR, et al. Competency-based medical education: Theory to practice. Med Teach 2010; 32:638-45.

6. Shah N, Desai C, Jorwekar G, Badyal D, Singh T. Competencybased medical education: An overview and application in pharmacology. Indian J Pharmacol 2016 Oct;48(Suppl 1): S5.

7. Nemoto T, Beglar D. Likert-scale questionnaires. In JALT 2013 Conference Proceedings 2014 (pp. 1-8).

8. Rustagi SM, Mohan C, Verma N, Nair BT. Competency-based Medical Education: The Perceptions of Faculty. J Med Acad 2019 Jan;2(1):2.

9. Kivunja C. Why Students Don't Like Assessment and How to Change Their Perceptions in 21 st Century Pedagogies. Creative Edu 2015;6(20):2117.

10. Salinitri FD, O'Connell MB, Garwood CL, Lehr VT, Abdallah $\mathrm{K}$. An objective structured clinical examination to assess problem-based learning. Am J Pharm Educ 2012;10;76(3).
11. Gruppen LD, Mangrulkar RS, Kolars JC. The promise of competency-based education in the health professions for improving global health. Human Resou Health 2012;10(1):43.

12. Kar M, Kar C, Roy H, Goyal P. Early clinical exposure as a learning tool to teach neuroanatomy for first-year MBBS students. Int J Appl Basic Med Res 2017;7(Suppl 1): S38.

13. Chari S, Gupta M, Gade S. The early clinical exposure experience motivates first-year MBBS students: A study. Int J Educ Sci $2015 ; 8(2): 403-5$.

14. Groopman J. How doctors think. Houghton Mifflin Harcourt; 2008 Mar 12.

15. Parsons T. The sick role and the role of the physician reconsidered. The Milbank Memorial Fund Quarterly. Health Soc 1975;8:257-78. 